Portland State University

PDXScholar

2-19-1993

\title{
Shapes of Venusian "Pancake" Domes Imply Episodic Emplacement and Silicic Composition
}

\author{
Jonathan H. Fink \\ Portland State University, jon.fink@pdx.edu \\ Nathan T. Bridges \\ Arizona State University \\ Robert E. Grimm \\ Arizona State University
}

Follow this and additional works at: https://pdxscholar.library.pdx.edu/geology_fac

Part of the Geology Commons, and the Volcanology Commons

Let us know how access to this document benefits you.

\section{Citation Details}

Fink, J. H., Bridges, N. T., \& Grimm, R. E. (1993). Shapes of Venusian "pancake" domes imply episodic emplacement and silicic composition. Geophysical research letters, 20(4), 261-264.

This Article is brought to you for free and open access. It has been accepted for inclusion in Geology Faculty Publications and Presentations by an authorized administrator of PDXScholar. Please contact us if we can make this document more accessible: pdxscholar@pdx.edu. 


\title{
SHAPES OF VENUSIAN "PANCAKE” DOMES IMPLY EPISODIC EMPLACEMENT AND SILICIC COMPOSITION
}

\author{
Jonathan H. Fink, Nathan T. Bridges ${ }^{1}$, and Robert E. Grimm \\ Department of Geology, Arizona State University
}

Abstract. The main evidence available for constraining the composition of the large circular "pancake" domes on Venus is eir gross morphology. Laboratory simulations using polyethne glycol show that the height to diameter (aspect) ratios of mes of a given total volume depend critically on whether their extrusion was continuous or episodic, with more episodes leading to greater cooling and taller domes. Thus without observations of their emplacement, the compositions of venusian domes cannot be uniquely constrained by their morphology. However, by considering a population of 51 venusian domes to epresent a sampling of many stages during the growth of domes with comparable histories, and by plotting aspect ratio versus total volume, we find that the shapes of the domes are most consistent with episodic emplacement. On Earth this mode of dome growth is found almost exclusively in lavas of dacite to thyolite composition, strengthening earlier inferences about the presence of evolved magmas on Venus.

\section{Introduction}

Among the most striking landforms revealed by Magellan images of Venus are the large, flat-topped, circular structures referred to informally as "pancake" domes. Based on their overall morphology, these have been widely interpreted to be silicic lava domes [e.g., Head et al., 1991; Pavri et al., 1992], an inference that has major implications for the crustal genesis of the planet. Here we evaluate this interpretation through a combination of scaling arguments, laboratory simulations, and field measurements of active silicic flows on Earth. Our modeling shows that the dimensions of an individual dome cannot be used to uniquely deduce either its composition or eruptive history. However the height $(\mathrm{H})$ to diameter $(\mathrm{D})$ ratios of the "pancakes", when considered as a group, are most consistent with their having been emplaced episodically rather than continuously, a mode of growth found on Earth primarily in magmas of dacitic to rhyolitic composition.

Dome shapes reflect a balance between the gravity-induced spreading of lava away from a vent and various forms of resistance to that outward flow. In previous models relating morphology to material properties, it was assumed that domes were made up of isothermal lava with either a Newtonian [Huppert, 1982], Bingham (viscoplastic) [Blake, 1990], or Coulomb [Johnson, 1970; Blake, 1990] rheology. In all these

Now at U.S. Geological Survey, Menlo Park

Copyright 1993 by the American Geophysical Union. cases, the viscosity of the lava controls the spreading rate but does not directly influence morphology. In the absence of cooling, Newtonian fluids spread indefinitely until ponded by topography, Bingham domes stop moving when the basal shear stress drops below the yield strength $\left(\tau_{0}\right)$, and Coulomb domes have a shape controlled by the angle of repose of the enclosing rubble, a property that is not directly related to composition. Because thicknesses of viscoplastic domes are proportional to their yield strengths which in turn generally increase with silica content, the Bingham model offers the possibility of relating remotely observed dome dimensions to chemistry. However, to be successful such interpretations must take cooling into account, because it also raises the strength of lava, primarily by forming a solid surface crust.

Venusian domes are much larger than most of their terrestrial counterparts. A convenient way to compare the geometry of different-sized viscoplastic domes on different planets is to plot their aspect ratios $(A=H / D)$ as a function of volume $(V)$. Slowly spreading circular domes with low strain rates should scale as [Blake, 1990; Bridges and Fink, 1992]:

$$
\mathrm{A}=\mathrm{k} \mathrm{V}-0.2 \tau_{0} 0.6 \rho^{-0.6} \mathrm{~g}^{-0.6}
$$

where $\rho$ is density, $\mathrm{g}$ is gravity, and $\mathrm{k}$ is a constant approximately equal to 1 . These relations imply that as any Bingham dome grows it should become progressively flatter. Furthermore, on a given planet, domes of equal volume should have aspect ratios proportional to the ratio of lava yield strength to density. Because yield strengths increase and densities decrease in proportion to silica content, the aspect ratio of a dome of given size should roughly reflect its composition. However, surface cooling also increases yield strength and thus influences dome shape. Thus without knowing the cooling history of a dome, we cannot uniquely relate its aspect ratio to composition.

\section{Growth of Terrestrial Domes}

Terrestrial domes have been separated into two types based on the way they erupt: continuous extrusions produce relatively low lava domes in which most growth is exogenous (new lava appears on the dome surface), while discontinuous extrusions separated by repose periods result in taller "Peléean" [Blake, 1990] domes in which much growth is endogenous (new lava enters and remains in the dome interior). Two well-documented eruptions illustrate how these different emplacement histories can influence dome shape. In 1979 a basaltic andesite dome grew continuously over 150 days in the crater of La Soufriere volcano on the island of St. Vincent [Huppert et al., 1982]. The dome's aspect ratio declined as its volume increased (Figure 1), closely following the trend described by (1) and implying that the yield strength remained nearly constant. In contrast, the dacitic Mount St. Helens (Washington) dome grew episodically 


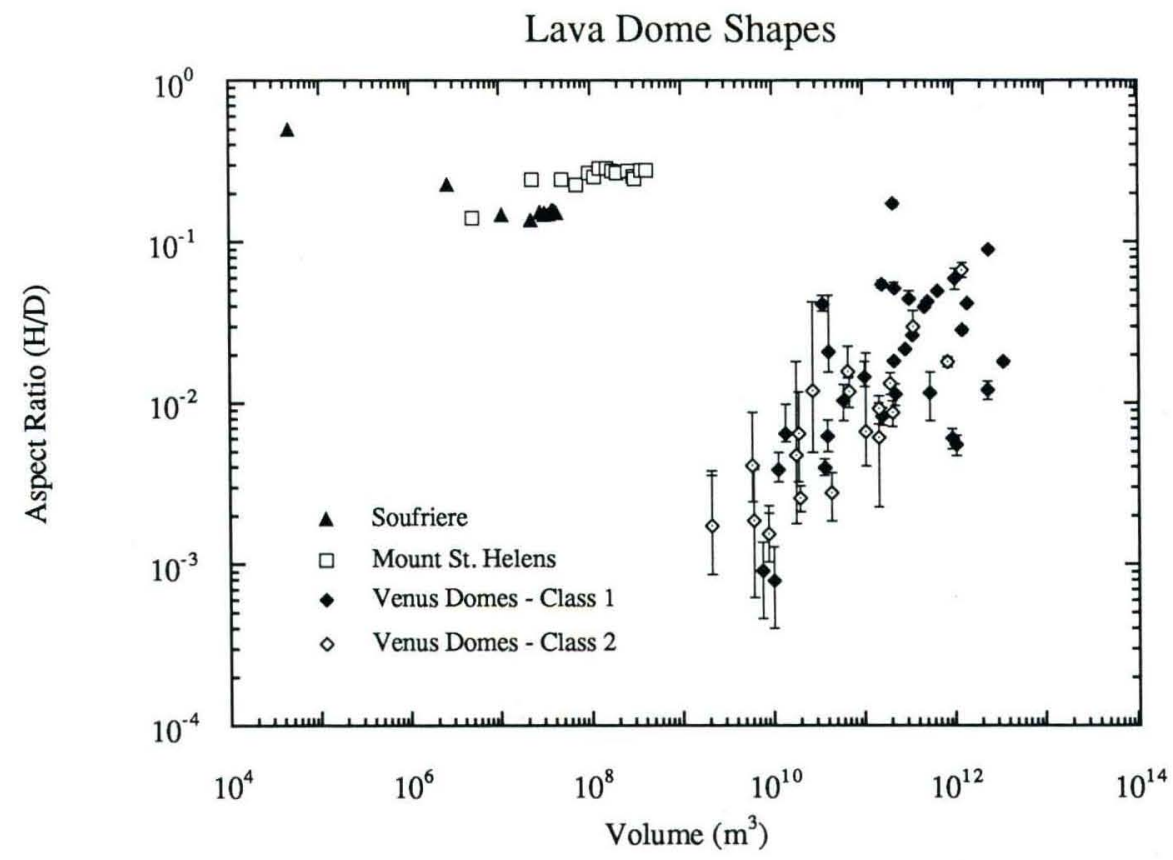

Fig. 1. Aspect ratio as a function of volume for continuously emplaced Soufriere dome, episodically emplaced Mount St. Helens dome, and 51 venusian domes. Slopes and regression

between October 1980 and October 1986, with 15 repose periods ranging from 32 to 354 days separating extrusive intervals lasting from 1 to 368 days [Swanson and Holcomb, 1990]. In this case, the aspect ratio increased along with dome volume; apparently the repose periods caused a significant rise in the effective yield strength, since the composition remained nearly constant. coefficients $\left(\mathrm{r}^{2}\right)$ are -0.17 and 0.97 for Soufriere and 0.12 and 0.62 for Mount St. Helens. Class 3 venusian domes are not shown because most of their heights could not be estimated.

\section{Laboratory Simulations of Dome Growth}

Laboratory simulations using analog materials confirm the relationships observed in active lava domes. In Figure 2 the solid circles show the evolution of a dome of polyethylene glycol wax (PEG) injected into a tank of relatively warm water. In the absence of cooling, PEG is a Newtonian fluid, and the

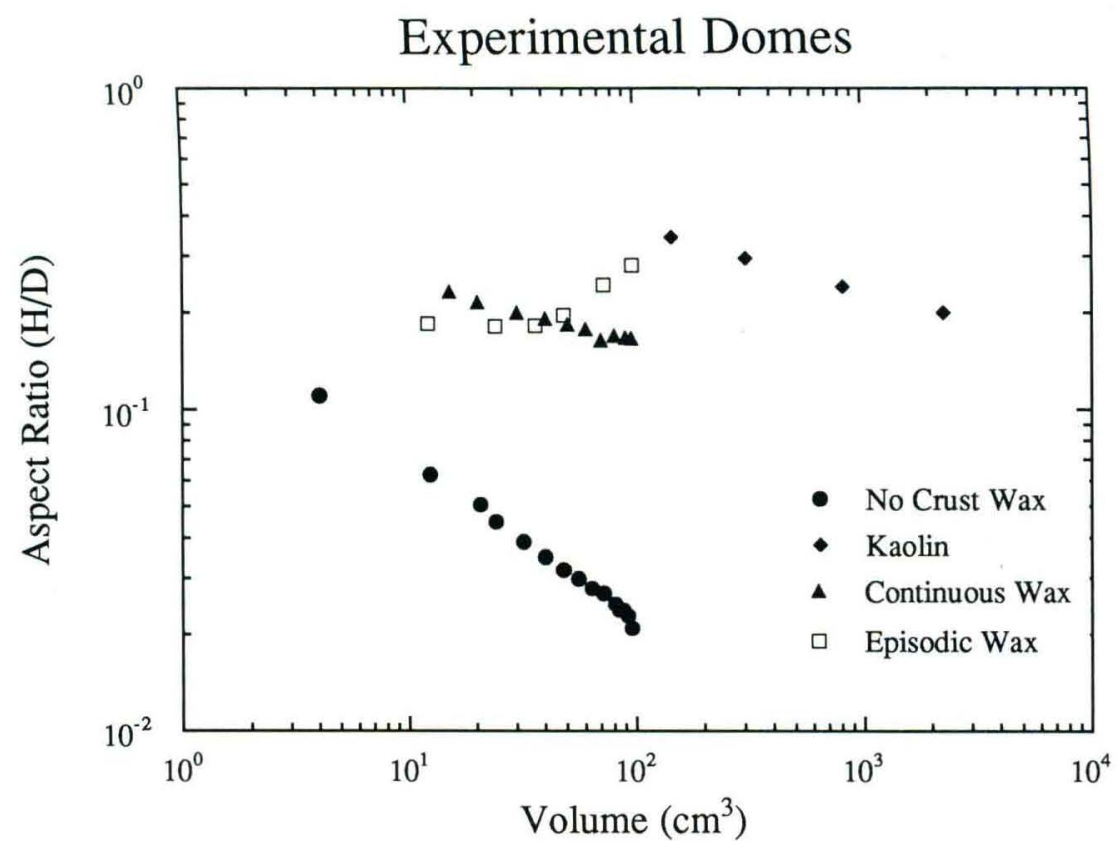

Fig. 2. Aspect ratio as a function of volume for three classes of polyethylene glycol (PEG) experiments [Bridges, 1992] and one kaolin experiment [Blake, 1990]. The "episodic" and "continuous" points are average values for three experiments each, while the "no crust" and "kaolin" points are each taken from one typical experiment. Slopes and regression coefficients $\left(\mathrm{r}^{2}\right)$ are
-0.50 and 0.99 for the "no crust" data, -0.20 and 0.99 for the kaolin data, -0.18 and 0.98 for the "continuous" data, and +0.20 and 0.71 for the "episodic" data. If the first two points for the episodic data are ignored (because cooling had not yet begunto increase the effective yield strength), then the slope is +0.45 and $r^{2}=0.99$. 
dome spreads almost exactly as predicted for viscous gravity currents [Huppert, 1982]. The solid diamonds represent the growth of a dome of isothermai viscuplastic kaolin slurry [Blake, 1990] and are consistent with (1). The solid triangles show average results from three experiments in which PEG was continuously injected into a tank of very cold water [Bridges, 1992]. Here solidification of the wax surface leads to Binghamlike behavior with an effective yield strength that remains nearly constant throughout emplacement. Finally, the open boxes show average results from three experiments in which $\mathrm{PEG}$ was injected episodically into cold water, with two-minute repose periods separating eight intervals of extrusion (Figure 3 ). Here the increasing aspect ratios reflect the enhanced cooling during repose periods. Individual episodic experiments also showed that the magnitude of aspect ratio increase was directly proportional to the number and length of repose periods [Bridges, 1992].

\section{Application to Venusian Domes}

Scaling analyses, analog experiments, and observations of active terrestrial extrusions demonstrate that the shapes of Bingham domes reflect effusion history as well as total volume, gravity, and composition. (The apparent lack of talus around most venusian domes allows us to ignore Coulomb behavior.) Thus without temporal data it is possible only to roughly constrain, not uniquely deduce, the composition of an individual venusian dome from its final geometry. However, because each dome grew through a sequence of aspect ratios before finally solidifying, the entire population of dome shapes should provide a "snapshot" of many of these earlier stages and thereby offer insight into the eruptive style (if the domes are all of the same composition). A group of continuously emplaced domes should plot within a region on Figure 1 that slopes down to the right, whereas an episodically emplaced group should slope up to the right. A mixture of both types of domes should form an ill-defined cluster.

To evaluate the applicability of this idea to the "pancakes",we made new height determinations for an earlier-identified set of 126 venusian domes [Pavri et al., 1992]. The mean dome diameter $(\sim 20 \mathrm{~km})$ is comparable to the typical footprint size and spacing (width and separation between imaging swaths on the venusian surface, both $\sim 12 \mathrm{~km}$ ), so special care had to be taken in correlating and interpreting height measurements. The widely-used, gridded altimetric data are smoothed, so that they can lead to underestimates of dome relief, or worse, misinterpre-
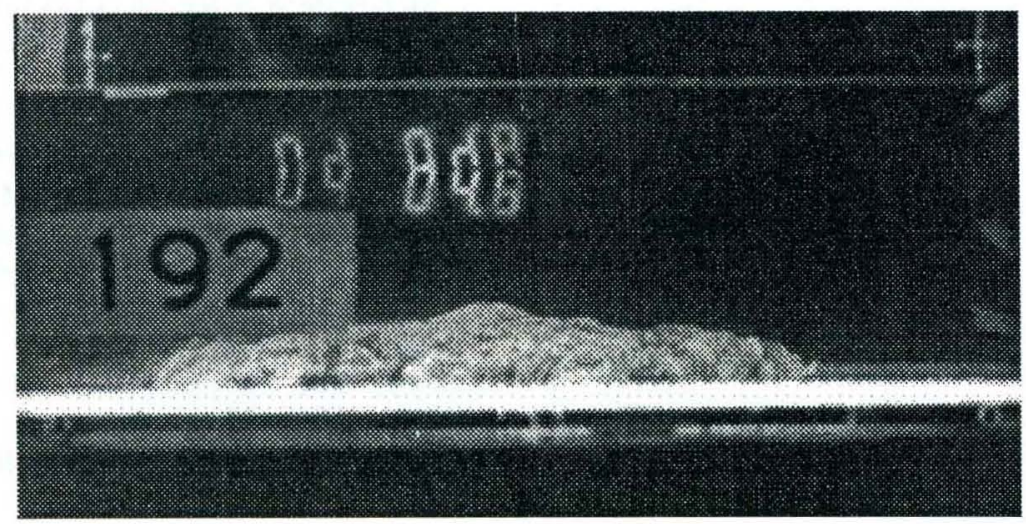

\section{Episode}

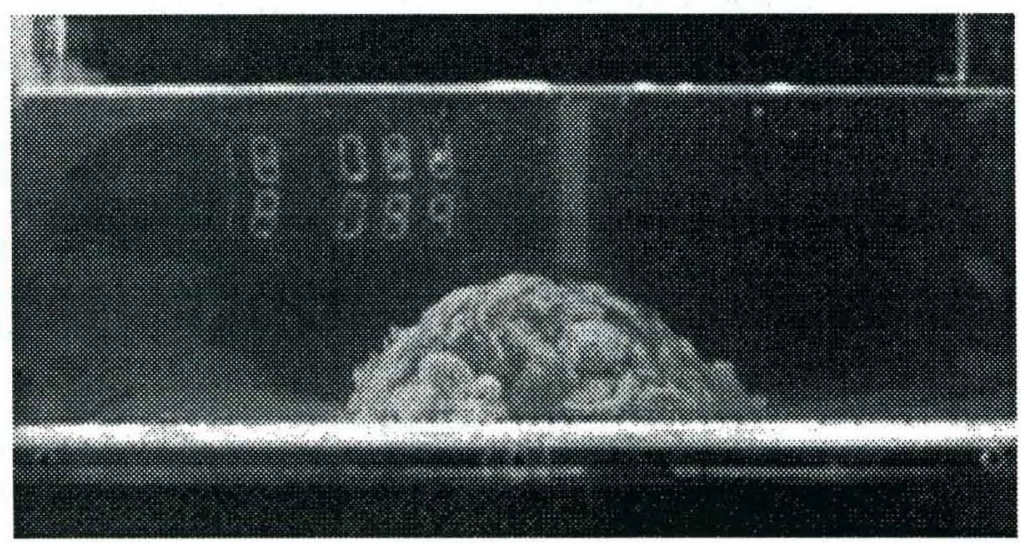

\section{Episodes}

Fig. 3. Side views of two simulated lava domes made of equal volumes of PEG but with different eruptive histories [Bridges, 1992]. In (a) wax was extruded continuously. In (b), wax was extruded through eight 30 -second episodes separated by 2 minute repose periods. Note the difference in aspect ratios. 
tation of adjacent features or data artifacts as dome topography. We used digital overlays of individual altimetric footprints [Pettingill et al., 1991] on synthetic aperture radar (SAR) images to provide precise collocation, more accurate height measurements, and better identification of spurious data. Still higher spatial resolution $(\sim 2 \mathrm{~km})$ profiles are possible [McKenzie et al., 1992] but require specialized reprocessing not performed here.

We evaluated four types of height-measurement errors: (1) those intrinsic to the altimeter (typically less than $10 \mathrm{~m}$ and thus negligible); (2) difficulties in identifying domes, regional slopes, and base levels in the altimetric profiles; (3) failure of the altimeter footprint to completely fall within the diameter of small domes; and (4) limitations of the radar-processing software in areas with complex radar properties. After quantifying these effects we grouped the data into three classes by inspection ( $1=$ high confidence, $3=$ low). Data for classes 1 and 2 are shown in Fig. 1, with high-resolution height measurements for 6 domes [McKenzie et al., 1992] substituted for the appropriate class 1 domes. The venusian domes clearly show a positive correlation between aspect ratio and volume, for both the highest and intermediate data classes. As we saw earlier, such a correlation strongly suggests episodic growth. Furthermore, the steep slope of the trend indicates that the domes grew through a large number of episodes with considerable cooling during repose periods.

This discontinuous emplacement was most likely driven by crystallization-induced volatile release, a process proposed for some terrestrial eruptions [Blake, 1984; Cashman, 1988; Anderson and Fink, 1989] because it can repeatedly generate "eruptible" batches of buoyant magma. The rate of volatile exsolution is in turn controlled by the composition of the magma and the temperature contrast between magma and host rocks. Episodic eruptions tend to occur when magma has a relatively difficult time making its way to the surface, due to some combination of tectonic stress state, high cooling rates which promote solidification, and/or high viscosity. These conditions are most likely to occur in areas of compression, in regions of low heat flow, and for magmas of silicic composition or high crystallinity, respectively. However, the distribution of large venusian domes shows no preference for areas characterized as having predominantly compressive stress regimes [Pavri et al., 1992], nor is there evidence that they are concentrated where other volcanic features are lacking, as might be expected in regions that have locally lower crustal temperatures. It thus seems most probable that episodic emplacement would be caused by high magma viscosity. This conclusion is consistent with the observation that steep-sided Peléean-type domes on Earth are most commonly made of magma whose composition ranges from dacite to rhyolite. Thus although the shapes of individual "pancake" domes on Venus cannot directly tell us about their compositions, the population as a whole strongly suggests discontinuous formation processes like those associated preferentially with silicic magmas on Earth.

Acknowledgements. Research supported by NASA Grant NAGW 529 from Planetary Geology and Geophysics Program and the National Science Foundation grant EAR 9018216.
Thanks to PeterFord, Betina Pavri, Michael Malin, Curt Manley, and Ross Griffiths for stimulating discussions.

\section{References}

Anderson, S. W. and J.H. Fink, Hydrogen-isotope evidence for extrusion mechanisms of the Mount St. Helens lava dome, Nature, 341, 521-523, 1989.

Blake, S., Viscoplastic models of lava domes, IAVCEI Proc. Volcan.vol. 2, J.H. Fink, ed., 88-126, Springer Verlag, New York, 1990.

Blake, S., Volatile oversaturation during the evolution of silicic magma chambers as an eruption trigger, J. Geophys. Res., 89, 8237-8244, 1984.

Bridges, N. T. and J.H. Fink, Aspect ratios of lava domes on the Earth, Moon and Venus, Lunar Planet. Sci. Conf. XXIII, 159-160, 1992.

Bridges, N. T., Laboratory models of lava domes [M.S. thesis] Arizona State University, Tempe, Arizona, 167 p., 1992.

Cashman, K. V., Crystallization of Mount St. Helens dacite: A quantitative textural approach, Bull. Volcanol., 50, 194. 209, 1988.

Head, J. W., D. W. Campbell, C. Elachi, J.E. Guest, D.P. McKenzie, R.S. Saunders, G.G. Schaber, and G. Schuber, Venus volcanism: Initial analysis from Magellan data, Science, 252, 276-288, 1991.

Huppert, H. E., The propagation of two-dimensional and axisymmetric viscous gravity currents over a rigid horizon. tal surface, J. Fluid Mech. 121, 43-58, 1982.

Huppert, H.E., J.B. Shepherd, H. Sigurdsson, and R.S.J.Sparks, On lava dome growth, with application to the 1979 lava extrusion of the Soufriere of St. Vincent, J.Volcan. Geotherm. Res., 14, 199-222, 1982.

Johnson, A.M., Physical Processes in Geology, Freeman Cooper, San Francisco, 1970.

McBirney, A. R. and T. Murase, Rheological properties of magmas, Ann. Rev. Earth Planet. Sci., 12, 337-357, 1984.

McKenzie, D., P.G. Ford, F. Liu, and G.H. Pettingill, Pancakelike domes on Venus, J. Geophys. Res., 97, 15,967-15,976, 1992.

Pavri, B., J.W. Head, K.B. Klose, and L. Wilson, Steep-sided domes on Venus: Characteristics, geologic setting, and eruption conditions from Magellan data, J. Geophys. Res, 92, 13445-13478, 1992.

Pettingill, G. H., P.G. Ford, W.T.K. Johnson, R.K. Raney, an L.A. Soderblom, Magellan: Radar performance and data products, Science, 252, 260-265, 1991.

Swanson, D. A. and R.T. Holcomb, Regularities in growth of the Mount St. Helens dacite dome, 1980-1986, IAVCEI Proc.Volcan. vol.2, J.H. Fink, ed., 1-24, Springer Verlag, New York, 1990.

N.T. Bridges, J. H. Fink, and R.E. Grimm, Geology Depar ment, Arizona State University, Tempe, AZ 85287-1404.

(Received December 1, 1992;

Accepted December 23, 1992.) 